\title{
Documentation errors in paediatric drug charts:
}

\section{An Audit}

Kankananarachchi I, ${ }^{1}$ Egodage UK, ${ }^{2}$ Dharmasiri K, ${ }^{3}$ Jayathilake E, ${ }^{4}$ Shanika $G,{ }^{5}$ Devasiri V, ${ }^{6}$

\begin{abstract}
INTRODUCTION:

Documentation errors leading to medication errors pose a health risk to hospitalised patents. Maintenance of the drug chart in hospitalized patients is done by nursing staff in Sri Lanka. This audit was carried out in a paediatric unit to assess documentation errors and nature of risk to patients.
\end{abstract}

\section{METHOD:}

Drug charts of 236 Bed Head Tickets (BHT) were analyzed over a period of one month in a single paediatric unit. Parameters of concern were generic and propriety names of drugs, spelling mistakes, abbreviations and legibility of handwriting.

\section{RESULTS:}

Total of 882 drugs were written in 236 BHTs. The mean number of drugs per one BHT was 3.7. At least one error was observed in 473 (53.6\%) names of drugs. 25\% (225) of drug documentations had spelling mistakes. In majority of cases with spelling mistakes, there was an error in one letter (88.8\%). Abbreviations, propriety names and illegible hand writing were written in 134 (15.1\%), 104 (11.7\%) and 18 (2\%) occasions respectively. Paracetamol was the most commonly documented drug and $30 \%$ of the time it was written in abbreviations. Most frequent spelling mistakes were seen in Clarithromycin (95\%) and Amoxicillin (74\%). Usage of trade name was commonly seen when writing Chlorpheniramine (26.5\%). The least number of spelling mistakes were seen in salbutamol (3\%).

\section{CONCLUSION:}

There was no standard practice of maintaining drug charts in hospitalized patients and it may pose a significant health risk. Authors would like to suggest doctors to take the responsibility of the maintenance of drug charts in order to minimize this high prevalence of documentation errors.

Key words: Medical error, Documentation error, Drug charts, Paediatrics

\section{Introduction}

Medication errors in hospitals could occur at various levels starting from procuring of medication to prescribing, dispensing, administering and monitoring its adverse effect.1 Prescription errors are a common health care problem all over the world. It is estimated that annually, 7000 mortalities in the world are due

1. Lecturer, Department of Paediatrics, Faculty of Medicine, University of Ruhuna

2. Lecturer, Department of Physiology, Faculty of Medicine, University of Ruhuna

3, 4, 5 Demonstrator, Department of Paediatrics, Faculty of Medicine, University of Ruhuna

6. Professor, Department of Paediatrics, Faculty of Medicine, University of Ruhuna

Corresponding author : Imalke Kankananarachchi; imalke462@gmail.com ;

https://orcid.org/0000-0002-9351-2966 to primary prescription errors. 2 There had been a few research attempts in the past to evaluate medication errors in paediatric population. 1,2,3,4 Children carry a high risk since there is a wide range in body weight, which warrants doses to be adjusted individually depend on age, weight and body surface area of the patient. 3 Moreover, paediatric population is at 3 times risk of having potentially harmful MEs compared to adults. 4 Although paediatric population is at the greatest risk for medication errors, little is known about the prevalence of such errors. Common identified medication errors are illegible handwriting, using abbreviations, spelling mistakes, writing in brand names, incorrect dosage and frequencies. 4

The study was carried out to identify the documentation errors in the drug charts of Bed Head Tickets (BHTs) and to assess whether the names of drugs were written according to the standards of British National Formulary, Paediatric version 2016 and to create an awareness regarding the irrational use of medications 


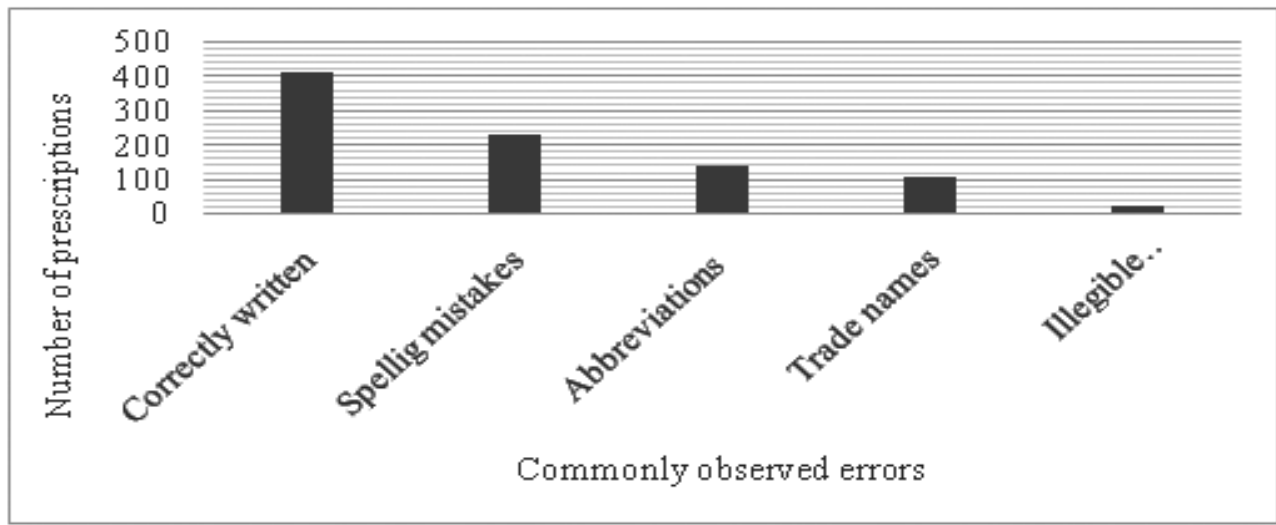

Figure 1 Different types of drug name documentation errors

Table 1 Types of errors in commonly used drugs

\begin{tabular}{|l|l|l|l|l|l|c|}
\hline Drug name & $\begin{array}{l}\text { Correctly } \\
\text { written }\end{array}$ & $\begin{array}{l}\text { Spelling } \\
\text { mistakes }\end{array}$ & $\begin{array}{l}\text { Abbreviat } \\
\text { ions }\end{array}$ & $\begin{array}{l}\text { Trade } \\
\text { names }\end{array}$ & $\begin{array}{l}\text { Illegible } \\
\text { writing }\end{array}$ & Total \\
\hline Paracetamol & $75(67.5 \%)$ & $02(1.8 \%)$ & $33(29.7 \%)$ & $01(0.9 \%)$ & $00(0 \%)$ & 111 \\
\hline Chlorpheniramine & $67(68.3 \%)$ & $05(5.1 \%)$ & $00(0 \%)$ & $26(26.5 \%)$ & $00(0 \%)$ & 98 \\
\hline Salbutamol & $84(94.3 \%)$ & $03(3.4 \%)$ & $00(0 \%)$ & $02(22.4 \%)$ & $00(0 \%)$ & 89 \\
\hline Prednisolone & $18(54.5 \%)$ & $14(42.4 \%)$ & $00(0 \%)$ & $00(0 \%)$ & $01(3.0 \%)$ & 33 \\
\hline Antibiotics & $102(44.1 \%)$ & $108(46.7 \%)$ & $01(0.4 \%)$ & $11(4.7 \%)$ & $09(3.6 \%)$ & 231 \\
\hline Antiemetics & $20(47.6 \%)$ & $12(28.5 \%)$ & $0(0 \%)$ & $9(21.4 \%)$ & $1(2.3 \%)$ & 42 \\
\hline Antiepileptics & $10(25.6 \%)$ & $11(28.2 \%)$ & $12(30.7 \%)$ & $3(7.6 \%)$ & $2(5.1 \%)$ & 39 \\
\hline
\end{tabular}

by providing the feedback to the healthcare professionals.

\section{Materials and methods}

A prospective clinical audit was conducted over a period between 1st March 2017 to 31st March 2017, in the University Paediatric Unit, teaching Hospital Karapitiya. All BHTs during the period were taken in to the study and the principal investigator analyzed names of the drugs written in the drug chart with the standard writing according to the British National Formulary 2016. Parameters concerned were name of the drug in generic form or trade name, spellings mistakes, abbreviations and legibility of hand writing. Spelling mistakes of trade names and abbreviations were not taken in to the analysis. Errors related to the dose, frequency and routes of administrations were not analysed in this study. When most or all letters of the drug are impossible to identify by the principal investigator and by one nursing officer, it was labelled as illegible handwriting.

\section{Results}

There were 236 BHTs over the given period and 882 drug names were written in it. The mean number of drugs per one BHT was 3.7. The most commonly prescribed drug was paracetamol, $n=111$ (12.5\%). In addition, chlorpheniramine, salbutamol and prednisolone were frequently prescribed amounting at $n=98$ $(11.1 \%), n=89(10.0 \%)$ and $n=33(3.7 \%)$ respectively. At least one form of error was observed in 473 (53.6\%) names, whereas 9 (1.0\%) drug names had more than one error. The most common prescription error was spelling mistakes, accounting for 225 (25\%). The prevalence of abbreviations was 134 (15.1\%) whereas, Trade/propriety names were written in 104 (11.7\%) occasions followed by illegible hand writing in 18 (2\%). (Figure 01)

The highest percentages of spelling mistakes were seen among antibiotics. Out of 231 antibiotic prescriptions, $46.7 \%(n=108)$ had spelling mistakes. (Table 01) The highest prevalence of spelling mistakes was seen in writing of clarithromycin $(95 \%)$ followed by amoxicillin (74\%) and cefotaxime (54\%). 
The least number of spelling mistakes were seen in salbutamol (3\%). In majority of cases with spelling mistakes, there was an error in one letter $(88.8 \%)$ followed by more than one letter in the rest.

Out of 111 prescriptions, in 33 (29.7\%) occasions paracetamol was written as "PCM". In addition, antiepileptics were commonly written with abbreviations. Usage of trade name was commonly seen when writing chlorpheniramine( $n=26,26.5 \%)$. Illegible hand writing was observed in $18(2 \%)$.

\section{Discussion}

Although there are no universal standards for writing prescriptions, every country has its own regulations.5 However, world health organization (WHO) recommendation is to write the name of the drug correctly in legible hand writing. 5 Moreover, it is recommended to write the prescription in generic form whenever possible in order to minimize drug dispensing errors. 5

According to the findings of this audit, at least one error was detected in more than half of the drugs names showing the magnitude of the problem. Of them, majority were related to spelling mistakes and which were common among antibiotics category. Since certain antibiotic classes such as cephalosporin have similar letters, spelling mistakes can result in incorrect administration of the drug. Since the impact of the prescription errors was not addressed in this study, it is difficult to comment on any adverse sequels of such mistakes. However, the prevalence of prescription errors in this audit was much more common than worldwide figures. According to a systematic review, the overall median prescribing error was $7 \%$ in hand written hospital prescriptions from 1985 to 2008.6 Unlike in most of the developed countries, in Sri Lanka, the drug chart of the BHT is maintained by the nursing staff, which would have contributed to the high error rates compared to other countries. Hence the authors would suggest that the maintenance of the drug chart be made the responsibility of the prescriber.

Though in this audit, the accuracy of drug doses was not taken in to the account, in most of the published studies, the commonest prescription error in children was problems related to the dosage.1,3,4 Therefore, if this audit expanded to evaluate the accuracy of drug dosage, error rate would have risen further. Moreover, it is important to carry out further studies or clinical audits to assess the accuracy of drug doses, frequency and the route of administration in future.

Some studies have looked in to the possible underlying reasons for documentation errors and have found that, inadequate knowledge, ignorance, inexperience staff and forgetfulness as leading contributory factors for medication errors.7,8 However, the aforementioned aspect was not assessed and it is important to conduct further research to evaluate the underlying reasons for this extent of prescription errors.

\section{Conclusion}

In conclusion, there was no standard practice of maintaining drug charts in hospitalized patients and this can potentially pose a serious health risk. An awareness campaign regarding documentation and maintenance of drug charts, should be offered to medical officers and nurses to improve this aspect of health care quality. It is strongly recommended that Sri Lanka should develop standards for the design of in- patient prescription charts. Finally, authors would like to suggest doctors to take the responsibility of the maintenance of drug charts in order to minimize this high prevalence of documentation errors.

\section{Authors declare no conflicts of interest}

Acknowledgements : Authors would like to acknowledge the support of doctors and nursing staff of University Paediatric Unit, Teaching Hospital Karapitiya.

\section{References}

1. P. Aspeden, J.A. Wolcot, R.L. Palugod, T. Bastein, Preventing Medication Errors, Institute of medicine, 2016. Brief Report in July 2006, https://iom. nationalacademies.org.

2. P.M. Goulding, Prevention of Medical Errors, 2016. https://www.nursece.com

3. Hartwig, S.C., Denger, S.D., \& Schneider, P.J. (1991) Severity-indexed, incident report-based medication error-reporting program. Am J Hosp Pharm, 48. 2611-2616

4. H.S. Babar, S. Hussain, Z. Maqsood, et al., Adherence to prescription format and compliance with who core prescribing indicators, J. Pharm. Sci. Res. 6 (4) (2014) 195e199.

5. De Vries TP, Henning RH, Hogerzeil HV, Fresle DA, Policy M, World Health Organization. Guide to good prescribing: a practical manual, 1994

6. Tully MP. Prescribing errors in hospital practice. British journal of clinical pharmacology. 2012 Oct;74(4):668-75.

7. Lederman RM, Parkes C. Systems failure in hospitals - using Reason's model to predict problems in a prescribing information system. J Med Syst. 2005; 29:33-43

8. Nichols P, Copeland TS, Craib IA, Hopkins P, Bruce DG. Learning from error: identifying contributory causes of medication errors in an Australian hospital. Med J Aust. 2008; 188:276-9. 